University of Nebraska - Lincoln

DigitalCommons@University of Nebraska - Lincoln

$9-9-2004$

\title{
Use of fecal glucocorticoid metabolite measures in conservation biology research: considerations for application and interpretation
}

Joshua J. Millspaugh

University of Missouri, Columbia, joshua.millspaugh@umontana.edu

Brian E. Washburn

USDA/APHIS/WS National Wildlife Research Center, brian.e.washburn@aphis.usda.gov

Follow this and additional works at: https://digitalcommons.unl.edu/icwdm_usdanwrc

Part of the Environmental Sciences Commons

Millspaugh, Joshua J. and Washburn, Brian E., "Use of fecal glucocorticoid metabolite measures in conservation biology research: considerations for application and interpretation" (2004). USDA National Wildlife Research Center - Staff Publications. 395.

https://digitalcommons.unl.edu/icwdm_usdanwrc/395

This Article is brought to you for free and open access by the U.S. Department of Agriculture: Animal and Plant Health Inspection Service at DigitalCommons@University of Nebraska - Lincoln. It has been accepted for inclusion in USDA National Wildlife Research Center - Staff Publications by an authorized administrator of DigitalCommons@University of Nebraska - Lincoln. 


\title{
Use of fecal glucocorticoid metabolite measures in conservation biology research: considerations for application and interpretation
}

\author{
Joshua J. Millspaugh ${ }^{\mathrm{a}, *}$, Brian E. Washburn ${ }^{\mathrm{b}}$ \\ ${ }^{a}$ Department of Fisheries and Wildlife Sciences, University of Missouri, 302 Natural Resources Building, Columbia, MO 65211, USA \\ ${ }^{\mathrm{b}}$ USDA, Wildlife Services, National Wildlife Research Center, 6100 Columbus Avenue, Sandusky, OH 44870, USA
}

Received 6 October 2003; revised 24 May 2004; accepted 14 July 2004

\begin{abstract}
Fecal glucocorticoid metabolite analyses are increasingly being used by a variety of scientists (e.g., conservation biologists, animal scientists) to examine glucocorticoid (i.e., stress hormone) secretion in domestic and wild vertebrates. Adrenocortical activity (i.e., stress response) is of interest to conservation biologists because stress can alter animal behavior, reduce resistance to disease, and affect population performance. The noninvasiveness of fecal-based assessments is attractive, particularly when studying endangered species, because samples can often be obtained without disturbing the animal. Despite such advantages, many confounding factors inhibit the utility of this technique in addressing conservation problems. In particular, interpretation of fecal glucocorticoid metabolite (FGM) measures may be confounded by the length of time animals are held in captivity, normal seasonal and daily rhythms, body condition, sample storage and treatment techniques, diet of the animal, assay selection, animal status (i.e., social ranking, reproductive status), sample age and condition, and sample mass. Further complicating interpretation and utility of these measures is the apparent species-specific response to these factors. The purpose of this paper is to discuss the factors that confound interpretation of FGM measures, summarize research that addresses these issues, and offer an agenda for future research and interpretation. We urge conservation biologists to carefully consider confounding factors and the relationship between FGM secretion and population performance and biological costs when investigating effects of environmental and human-induced disturbances on wildlife. The crisis nature of many decisions in conservation biology often requires decisions from limited data; however, confirmatory results should not be posited when data are incomplete or confounding factors are not understood. Building reliable databases, and research with surrogate species when possible, will aid future efforts and enhance the utility of FGM assays.
\end{abstract}

(c) 2004 Elsevier Inc. All rights reserved.

Keywords: ACTH challenge; Conservation biology; Corticosterone; Cortisol; Feces; Fecal glucocorticoids; Physiology; Noninvasive; Stress; Stress response; Wildlife

\section{Introduction}

Because of potentially deleterious effects of chronic stress, there is great interest among different fields of study in measuring animal stress. Conservation biologists are often concerned with mitigating effects of envi-

\footnotetext{
* Corresponding author. Fax: +1 5738845070.

E-mail address: millspaughj@missouri.edu (J.J. Millspaugh).
}

ronmental conditions and human-induced disturbances on wildlife (e.g., Foley et al., 2001; Millspaugh et al., 2001; Tempel and Gutiérrez, 2003). For animals in zoos, effects of an animal's surroundings, such as space and food availability, and social conditions (e.g., Wielebnowski et al., 2002) are often of interest. For domestic species, animal scientists consider animal surroundings (Barnett et al., 1991; Craig and Craig, 1985), effects of painful events (Merl et al., 2000), and responses to 
transportation (Möstl et al., 2002; Palme et al., 2000) and subsequent effects on meat quality (Ewing et al., 1999). Thus, the effects of stress have important conservation and economic implications.

A major challenge is quantifying 'stress' in animals. In addition to behavioral measures (Rushen, 2000), endocrine and immunological techniques have been used to measure stress responses. Commonly, glucocorticoid (i.e., cortisol and corticosterone) secretion is used as a hormonal measure of stress (Wasser et al., 2000; Wingfield et al., 1994). In the past, glucocorticoids have typically been quantified in blood (e.g., Gregory and Schmid, 2001; Harlow et al., 1990; Hood et al., 1998; Mathies et al., 2001; Widmaier et al., 1994; Wingfield et al., 1994). Blood-based assays (serum or plasma) measure the level of glucocorticoids available to trigger biological responses in the animal (Washburn et al., 2002; Wingfield et al., 1994). However, use of blood measures is restrictive for many species because animals typically must first be captured, thus potentially compromising an accurate assessment of stress (Cook et al., 2000; Hamilton and Weeks, 1985; Le Maho et al., 1992). Recent developments, such as remote blood sampling systems are helpful (Cook et al., 2000), but are not feasible in most field studies involving free-ranging animals. In addition, the point sample provided by a blood measure might not be representative of long-term hormone levels due to the pulsatile secretion pattern of glucocorticoids in blood (Harper and Austad, 2000; Monfort et al., 1993; Windle et al., 1998). On the other hand, blood measures offer the advantage of evaluating adrenal responsiveness to a capture and restraint protocol (Wingfield et al., 1994), which aids in understanding the animal's adrenocortical status.

In contrast to blood measures, noninvasive methods to quantify stress are being developed and applied in vertebrate studies which offer several advantages over traditional invasive methods. Fecal hormone metabolite assays are now being used in a variety of disciplines (e.g., animal science, behavioral ecology, conservation biology, ornithology, and primatology) to examine the reproductive and adrenocortical status of a variety of taxa (Berkeley et al., 1997; Dehnhard et al., 2001, 2003; Ganswindt et al., 2003; Good et al., 2003; Goymann et al., 1999, 2002; Graham and Brown, 1996; Harper and Austad, 2000; Hayssen et al., 2002; Hunt et al., 2004; Jurke et al., 1997; Kirkpatrick et al., 1996; Miller et al., 1991; Morrow et al., 2002; Palme and Möstl, 1997; Touma et al., 2003, 2004; Turner et al., 2003; Wasser et al., 1997, 2000). These noninvasive methods are particularly useful because samples can be easily obtained without disturbing the study animals and do not put the animal in danger during capture (Millspaugh et al., 2002; Möstl and Palme, 2002; Wasser et al., 2000). Furthermore, samples can be collected at regular intervals through time. Because they do not disturb the animal, noninvasive techniques may provide an accurate assessment of stress without the bias of capture-induced increases in glucocorticoids (Harper and Austad, 2000; Millspaugh et al., 2001; Touma et al., 2003). Furthermore, fecal glucocorticoid metabolite (FGM) assays reflect an average level of circulating glucocorticoids over a time period, rather than a point sample, and therefore may provide a more accurate assessment of long-term glucocorticoid levels (Harper and Austad, 2000).

Although use of noninvasive techniques has increased for many species, several confounding factors inhibit their utility. Thus, interpretation of studies remains problematic. For example, FGM measures may be affected by sampling issues and assay artifacts such as sample age (Washburn and Millspaugh, 2002), time of day the sample was obtained (Touma et al., 2003), and short- and long-term storage techniques (Khan et al., 2002; Lynch et al., 2003; Millspaugh et al., 2003; Terio et al., 2002). A host of biological issues including length of time in captivity (Marra et al., 1995), normal daily (Breuner et al., 1999; Romero and Remage-Healey, 2000) and normal seasonal changes in glucocorticoid excretion (Dawson and Howe, 1983; Raminelli et al., 2001; Wingfield, 1994), reproductive status (Whittier et al., 1997; Wingfield et al., 1994), sex (Touma et al., 2003), body condition (Heath and Dufty, 1998; Smith et al., 1994), and the animal's diet might also confuse interpretation of FGM measures. The lack of available seasonal basal FGM values also has been inhibitive. That is, without knowledge of 'normal' values, it becomes difficult to assess whether FGM levels are elevated. More troubling is our inability to relate FGM measures to population performance (i.e., what range of glucocorticoid levels for what period of time indicates significant biological costs; 'distress')?

Data on 'normal' patterns of FGM excretion, an evaluation of potential confounding factors in regard to their affect on measured FGM levels, and an understanding of FGM levels in relation to response variables of interest (e.g., population performance) is essential for conservation biology. Without this information, the influence of natural or human-induced effects on wildlife populations becomes difficult to assess. Although some recent work has addressed these issues (e.g., Harper and Austad, 2001; Khan et al., 2002; Lynch et al., 2003; Millspaugh and Washburn, 2003; Touma et al., 2003; Washburn and Millspaugh, 2002), additional research is needed to understand their effects on FGM measurements over a broader range of conditions and species. In addition, the apparent species-specific response to these factors limits generalizing and applying results from one study to another.

We discuss confounding factors when using FGM assays to assess the adrenocortical status of free-ranging, wild animals and offer suggestions for future research. Data available on biological issues in FGM evaluation 
including effects of sex, age, reproductive status, daily and seasonal rhythms, effects of captivity, diet, and excretion route are summarized. Our paper is written in the context of addressing conservation problems, particularly with free-ranging species of conservation concern. However, many of our recommendations apply equally well to domestic and wildlife held in captivity.

\section{Issues with application and interpretation}

There are a number of sampling issues, assay artifacts, and biological conditions that complicate interpretation and application of FGM assay results. Here, we review the literature and offer guidance about these issues.

\subsection{Sampling and assay artifacts}

\subsubsection{Effects of sample age and condition}

Ideally, feces collected for FGM analysis would be of known age, from a known individual; however, this is often difficult in field studies. The most attractive sampling option for many elusive species involves the collection of fecal samples that are potentially several days old. Collecting non-fresh samples assumes that feces still contain biologically representative amounts of FGMs. However, samples that have been exposed to precipitation or excessive temperatures might not provide an accurate assessment of FGM levels.

Under controlled conditions, Washburn and Millspaugh (2002) found that white-tailed deer (Odocoileus virginianus) feces exposed to simulated rainfall events had artificially elevated FGM measurements. These differences were evident in samples exposed to rainfall for only a few days (Washburn and Millspaugh, 2002). They observed no temperature-related effects on FGM measurements. Washburn and Millspaugh (2002) suspected microbes in the feces may have metabolized the fecal glucocorticoids into metabolites with an increased relative affinity for the ICN corticosterone double-antibody radioimmunoassay kit (07-120102; MP Biomedicals, Costa Mesa, CA) used in their study. The ICN antibody they used is believed to act as a group specific antibody with cross-reactivity to numerous FGMs of both cortisol and corticosterone (Wasser et al., 2000). The additional moisture provided by the rainfall at room temperature may have provided a growth environment for microbes and detritivores, as evidenced by the presence of fungi observed on several fecal samples exposed to the simulated rainfall treatment (Washburn and Millspaugh, 2002). Also, other biochemical processes, such as cleavage of conjugate side groups from glucocorticoid metabolites by non-microbial action or release of FGMs from lipid micelles, may also have increased FGM measurements (Washburn and Millspaugh,
2002). Terio et al. (2002) found that glucocorticoid metabolites in cheetah (Acinonyx jubatus) feces decreased in response to sample drying with a solar oven and a conventional oven. Terio et al. (2002) reported these differences could be related to biochemical changes in immunoreactivity, degradation of steroids (Matkovics, 1972), or bacterial metabolism (Woods, 1975).

These results have important implications for field studies. First, these findings indicate the possibility of erroneous FGM measures from feces that are not collected fresh. Therefore, ideally one would collect only fresh samples (i.e., those less than a couple hours old), which is extremely difficult to know in field studies involving plot-based collection techniques. Because FGMs can change in short periods of time (Möstl et al., 1999; Washburn and Millspaugh, 2002), this suggestion must be taken seriously. Furthermore, samples collected blindly from plots could be from different animals of different ages, sex, reproductive conditions, body conditions, and hydration states, which could introduce unknown bias in any study using this design. When a researcher is unable to collect fresh samples, they must understand and acknowledge the effects of sample age and condition on FGM concentrations. We recommend future studies be conducted with fecal samples exposed to actual climatic conditions in field situations, involve other wildlife species, and be extended longer than 7 days.

\subsubsection{Sample storage and transportation}

Fecal samples used for FGM analysis are sometimes stored in preservatives, such as ethanol, prior to freezing; in some cases, shipping regulations require treatment. For example, if fecal material is shipped into the US, the US Department of Agriculture requires that feces be treated with heat or chemicals to kill potential pathogens (e.g., virus particles) to prevent disease transmission (Millspaugh et al., 2003). Approved treatments consist of autoclaving or immersing fecal material in $10 \%$ formalin, $2 \%$ acetic acid, $90 \%$ ethanol, or $2 \%$ sodium hydroxide. However, these treatments could influence the structure and immunoreactivity of FGMs, thus preventing accurate measurement of FGM levels. Millspaugh et al. (2003) evaluated whether these heat and chemical treatments influenced FGM concentrations in white-tailed deer and elk (Cervus elaphus) feces. They found that FGM measurements were consistently altered by autoclaving, often increasing FGM concentrations by $>20 \%$. They suspected increased microbial activity during the heating process or increased chemical reactions in the feces might have altered FGM levels (Aldercreutz et al., 1976; Bokkenheuser and Winter, 1980). Similarly, increased FGM concentrations in untreated, shipped deer feces were observed, which was attributed to sample thawing and warming, and subsequent microbial effects (Millspaugh et al., 2003). 
Formalin decreased FGM concentrations in deer and elk feces; sodium hydroxide reduced FGM concentrations in elk feces only. Immersing deer and elk samples in a $2 \%$ acetic acid treatment had the least impact on FGM measures; on average these samples were $<2 \%$ different from the control for deer and $<6 \%$ for elk. In a similar study, Terio et al. (2002) evaluated the effects of heat and chemicals on FGM levels in cheetah feces. They reported that ethanol was the best chemical treatment of those evaluated. Even untreated and frozen samples might have altered FGM levels. When frozen for a short-time (2 weeks), Lynch et al. (2003) observed a slight but significant decline to FGM in baboon (Papio cynocephalus) fecal samples; storage in a charcoal refrigerator increased FGM. Similarly, for baboon feces, Khan et al. (2002) observed differences in FGM levels from samples stored in ethanol at -20 and $25^{\circ} \mathrm{C}$, initially declining, then increasing at about 120 days; final FGM values at 180 days were similar to initial values (Khan et al., 2002).

These findings demonstrate that handling and storage of fecal samples might influence FGM measures; responses also could be species-specific. To slow microbial activity and reduce problems with immunoreactivity, we recommend freezing samples as soon as possible without any chemical treatment. When possible, use of liquid nitrogen and dry ice is advised because FGM can change in a very short time period (Möstl et al., 1999). If chemical treatment is required, a thorough understanding of their effects on FGM is necessary. If other hormone metabolites (e.g., fecal estrogens) are also being quantified from the fecal material, researchers should evaluate these effects for each hormone being measured because their response to chemicals might be different (Khan et al., 2002). Even in samples not treated with chemicals, the best approach to avoid alteration of FGM is prompt lyophilization and extraction to avoid effects due to freezing alone (Lynch et al., 2003). Careful consideration should be taken to understand length of storage in relation to FGM levels (e.g., Khan et al., 2002) because comparison of samples stored for different time periods might not be appropriate due to storage effects on FGM levels. More research should consider different species, shorter and longer storage in chemicals, and whether samples remain frozen or not.

\subsubsection{Variability in FGM measures}

Two additional sources of variability in FGM studies relate to the representativeness of the sub-sample selected for extraction and analysis (i.e., variability of multiple FGM estimates from the same individual fecal mass) and to the precision of the assay procedure itself. The first error might exist when FGMs are not evenly distributed throughout the entire fecal mass. An estimate of FGMs from a fecal sample is typically obtained by analyzing only one small aliquot (e.g., $\sim 0.2 \mathrm{~g}$ of dried feces) of the total fecal mass (Millspaugh et al., 2002; Wasser et al., 2000). Thus, the validity of FGM estimates depend upon the representativeness of that small aliquot used. For small species sampled via live-trapping or mist-netting it is feasible to collect and assay all fecal material deposited in a set amount of time. Estimates of variability are important because if variability is high, additional samples might be required to achieve a desired level of statistical power (Millspaugh and Washburn, 2003), should hypothesis testing be of interest.

Data on other fecal steroids suggest that FGMs could be different among portions of the fecal mass. For example, Brown et al. (1994) reported that fecal estrogens and progestins were unevenly distributed within feces of cheetahs, clouded leopards (Neofelis nebulosa), and snow leopards (Panthera uncia). Wasser et al. (1996) examined the distribution of radiolabeled estrogen and progesterone metabolites in African elephant feces and found concentrations were higher on the outside of the sample compared to the inside. Consequently, Wasser et al. (1996) recommended using well-mixed, dried fecal powder from premixed wet samples, which is the standard for FGM assays (e.g., Millspaugh et al., 2002; Wasser et al., 2000).

In a study designed to investigate variability in FGMs, Millspaugh and Washburn (2003) observed higher FGM measures from pellet groups than from thoroughly mixed fecal samples. Thus, using a few pellets from a fecal mass versus mixing that mass and sub-sampling, could lead to biased results. Additionally, FGM measures from thoroughly mixed fecal samples were less variable, although the result was not statistically significant. Despite the non-significance, a power analysis indicated the need to sample more intensively if thoroughly mixed fecal samples are not used during the extraction process. They also noted process error (i.e., repeatability of measurements) of $6-10 \%$ on average, but some samples, particularly those from pellet groups were much higher (i.e., 30\% difference). Such variability should be considered in light of measurable variance introduced by the disturbance effects of interest. We recommend researchers thoroughly mix the fecal mass in the field prior to sub-sampling fecal material for later laboratory analysis (Wasser et al., 1996).

\subsubsection{Sample mass}

In some situations, particularly those involving small animals (e.g., songbirds), the entire individual fecal mass may constitute the sample (Tempel and Gutiérrez, 2004; Washburn et al., 2003). Recent work from our laboratory suggests that very small fecal samples (e.g., $<0.02 \mathrm{~g}$ ) may result in proportionately higher FGM concentrations and thus might bias study findings (Fig. 1). Tempel and Gutiérrez (2004) found a similar relationship between small fecal samples and FGM concentrations in California spotted owl feces. The reason for 


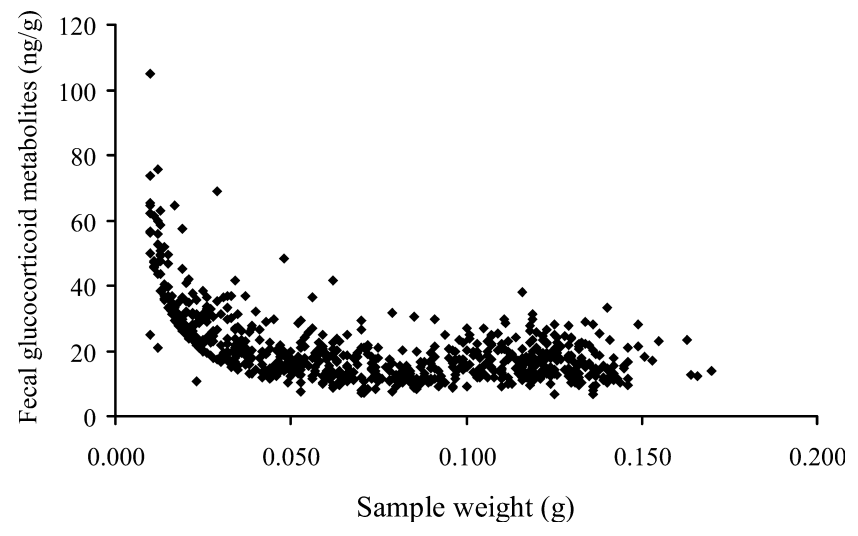

Fig. 1. The relationship between sample mass (g) and fecal glucocorticoid metabolite (ng/g) values from mourning dove (Zenaida macroura) feces. Feces were collected (within $1 \mathrm{~h}$ of defecation) from wildcaught birds held in captivity for a diversity of ecological studies.

this bias is unknown, but several possibilities exist. For one, the higher concentration of methanol per unit of sample mass might result in greater extraction of FGM from the dried feces during the extraction process. We believe future research needs to be conducted to provide guidance into the appropriateness of using fecal samples of very small mass. However, given the aforementioned findings in our laboratory, we suggest that researchers avoid analyzing fecal samples of very small mass $(<0.02 \mathrm{~g}$ dried mass) or, if appropriate, combine all fecal samples from a certain time period to provide a larger fecal sample representative of that time period (e.g., Suedkamp Wells et al., 2003).

\subsubsection{Antibodylassay selection and comparison}

Few studies have directly compared the effectiveness of two or more immunoassays for individual species, although some studies do exist (Goymann et al., 1999; Morrow et al., 2002; Wasser et al., 2000). Because each assay utilizes a different antibody with varying affinity for FGMs and differing methods for sample preparation may be used, it is not appropriate to compare absolute FGM values from two different studies if two different assays were used. In fact, unless standardized field sampling (e.g., storage in chemicals, age of sample) and lab techniques are used (e.g., method of extraction), direct comparisons of absolute FGM measures among studies should be conducted with caution. However, biologically important trends in FGM levels should be noted by both assays and allow for a comparison of trends.

The proportion and composition of circulating glucocorticoids in the bloodstream varies among species. For example, corticosterone is the primary glucocorticoid in birds and small mammals, whereas cortisol is the predominant glucocorticoid in medium to large mammals, fish, and humans (Hadley, 1996). There are some important exceptions concerning the primary glucocorticoid in certain groups of animals, which influences immunoas- say selection. For example, cortisol is the primary glucocorticoid in guinea pigs. Consequently, a spectrum of FGMs exists among species due to the variation in blood glucocorticoids, liver metabolic pathways, and gut microbial communities. Due to the spectrum of FGMs and species-specific responses to environmental conditions and anthropogenic influences, direct comparisons among species are not appropriate (Romero, 2004).

\subsection{Biological issues}

There are a number of biologically relevant issues that complicate interpretation of FGM research results. Here, we consider several biological issues such as effects of sex, age, and reproductive status, daily patterns and seasonal patterns in glucocorticoids, effects of captivity, dietary effects, excretion routes of glucocorticoid metabolites, and species-specific responses in stress responses.

\subsubsection{Sex, age, and reproductive status}

The sex, age, and reproductive status of an animal might influence its adrenocortical activity, with subsequent effects to FGM assessment. Romero and Remage-Healey (2000) found that male and female European starlings (Sturnus vulgaris) vary in their adrenocortical response to capture and handling during the breeding season. The adrenocortical response of juvenile Western screech owls (Otus kennicottii) to handling is slightly different from adult birds (Dufty and Belthoff, 1997). Touma et al. (2003) found that male mice (Mus musculus) excrete a higher proportion of radiolabeled corticosterone metabolites in feces compared to females. Reproductive status may also influence an animal's baseline FGM levels. For example, Kenagy and Place (2000) found that circulating glucocorticoid levels were significantly elevated in female yellow-pine chipmunks (Tamias amoenus) that were lactating; this elevation is likely reflected in FGM levels as well. In contrast, Huber et al. (2003) found that reproductive stage did not influence FGM levels in captive red deer.

These findings suggest that sex, age, and reproductive status can be expected to alter baseline FGM levels, which might influence interpretation of an animal's response to various stressors. Consequently, the best scenario would involve collection and analysis of samples from individuals of known sex, age, and reproductive status to ensure valid comparisons. Collection of samples from unknown individuals could bias results if differences exist by sex, age, and reproductive status and the researcher knows nothing about the animal from which samples were collected. In situations where sex of the animals that produced the fecal samples is unknown, other noninvasive techniques, such as determination of reproductive steroid concentrations for sex determination, might be helpful (Bercovitz et al., 1978; Washburn et al., 2004). 


\subsubsection{Daily rhythms and seasonal patterns in glucocor-} ticoid secretion

A distinct daily rhythm of basal levels of circulating glucocorticoids has been reported for numerous wildlife species, including pigeons (Columba livia; Joseph and Meier, 1973), Western screech owls (Dufty and Belthoff, 1997), white-crowned sparrows (Zonotrichia leucophrys) (Breuner et al., 1999), European starlings (Romero and Remage-Healey, 2000), and common marmosets (Callithrix jacchus) (Raminelli et al., 2001). Fecal glucocorticoid metabolites may follow a similar pattern because changes in FGM levels result from changes in circulating glucocorticoid concentrations. For example, Touma et al. (2003) reported that mice FGMs varied by time of day. Similarly, Raminelli et al. (2001) noted diurnal variation in fecal cortisol excretion in common marmosets with lower levels in morning and higher levels in afternoon. The detectability of diurnal changes in FGM may be related to lag time of FGM excretion, which is affected by gut passage time. That is, for small species such as mice where FGMs are excreted more rapidly, and defecation occurs at a more frequent rate, it is likely one could detect daily differences in FGM. For species with longer gut passive times (e.g., large ruminants) or those that defecate infrequently (e.g., reptiles), it might prove more difficult or impossible to detect daily differences. Researchers should incorporate knowledge of daily rhythms of FGM when interpreting results of FGM assays and might attempt to collect samples at the same time of day to avoid complications should diurnal differences be evident (Whitten et al., 1998). Comparison of FGM from fecal material collected at different times of the day will be valid only if FGMs do not reflect diurnal differences.

Recent research indicates that glucocorticoid levels in birds, mammals, reptiles, and amphibians are seasonally modulated (Harper and Austad, 2001; Kenagy and Place, 2000; Millspaugh et al., 2001; Moore et al., 2001; Romero, 2002). That is, the magnitude of both basal and elevated glucocorticoid levels might vary in a predictable pattern during the annual cycle. For example, studies of white-crowned sparrows have shown that baseline plasma corticosterone levels are lowest during the winter and periods of molting and highest during periods of active breeding (Astheimer et al., 1992; Romero et al., 1997; Romero and Wingfield, 1998d). Similarly, seasonal variation in plasma corticosterone (Romero, 2002; Romero and Remage-Healey, 2000; Romero et al., 1998a,b,c; Wingfield et al., 1994) and FGMs (Washburn et al., 2003) have been reported for other avian species. Seasonal patterns of glucocorticoids (Kenagy and Place, 2000; Romero, 2002) and FGMs (Harper and Austad, 2001; Millspaugh et al., 2001, 2002) are evident for various mammals.

Researchers should incorporate knowledge of seasonal patterns of glucocorticoid metabolites when inter- preting the results of FGM assays. Unfortunately, such data are unavailable for many species to which FGM analyses have been applied. For many other species for which FGM analyses may be ideal, there is little information regarding basal seasonal levels of FGM. Based on the available data (see Romero, 2002 for review), we should expect such normal seasonal differences in FGMs. However, without knowledge of normal seasonal FGM levels, it becomes difficult to assess whether or not observed differences in FGMs are 'normal' or due to a treatment effect (e.g., human disturbance). That is, simply because one notes elevated FGMs during a particular season does not imply that elevation is due to some external stressor; rather it could be a normal physiological event (Millspaugh et al., 2001). Good experimental design, including use of controls, replication, and randomization of treatments helps in this regard, but a better understanding of seasonal rhythms in FGMs is needed.

\subsubsection{Effects of captivity}

Often, wild animals are captured and held in captivity to better understand FGMs (Washburn et al., 2003) or to evaluate the effects of potential stressors on the animal (Suedkamp Wells et al., 2003). However, wild animals in captivity may exhibit FGM levels that are higher or even lower than free-ranging conspecifics and might respond differently to treatments. Previous research suggests wild birds placed in captivity typically have plasma corticosterone levels that are higher compared to free-ranging individuals of the same species (Marra et al., 1995; Romero and Wingfield, 1999; Wingfield et al., 1982). Romero and Wingfield (1999) found that captivity influences the hypothalamic-pituitary-adrenal (HPA) axis in white-crowned sparrows. Studies of white-crowned sparrows and white-throated sparrows (Zonotrichia albicollis) brought into captivity and held in outdoor cages suggest more than 35 days is required for these birds to acclimate to captivity (Marra et al., 1995; Romero and Wingfield, 1999).

As the length of time a wild-caught individual spends in captivity increases, basal corticosterone levels decrease as the birds acclimate to captivity (Wingfield et al., 1982). Piersma and Ramenofsky (1998) found a similar response of decreasing plasma corticosterone levels over time in migratory shorebirds following placement into captivity. Because FGM levels are a reflection of circulating glucocorticoid concentrations, captivity may also increase FGM concentrations in wild caught animals. Washburn et al. (2003) reported that in captive mourning doves, FGM levels were higher during the initial few months of captivity and decreased to comparatively lower levels by 6 months after entering into captivity.

The collective findings of these studies suggest the duration wild-caught individuals spend in captivity 
influences their basal FGM levels and responsiveness to stimuli. Researchers should recognize that individual species might respond differently to captivity and the period of acclimation might be quite variable. Any study using captive animals should attempt to determine time to acclimation and incorporate this information in subsequent studies. A main benefit of using wild-caught animals held in captivity is the ability to experimentally test effects of various stressors. However, if captive animals have not had sufficient time to acclimate, their response to various stimuli might be altered by their already artificial level of FGMs. Captive studies could play a vital role in better understanding FGMs of wild animals if they provide reliable information regarding wild animal FGM patterns and responses to treatments. However, there is a real danger in applying the results of FGM studies from animals held in captivity when those animals' adrenocortical status, response, and glucocorticoid secretion patterns do not mimic wild animals.

\subsubsection{Effects of diet}

Fecal glucocorticoid metabolite measures might be influenced by animal diets. For wild animals, availability and nutritional value of food resources changes seasonally. Consequently, corresponding differences in intake of various dietary components can be expected. Such changes in diet could affect FGM measurements. For example, studies of humans suggest dietary fiber can decrease gut transit time while increasing fecal bulk, which increases total fecal estrogen concentrations in women (Goldin et al., 1981, 1982). Dietary fiber or other nutritional parameters might also influence FGM concentrations by influencing gut microbial metabolism of glucocorticoid metabolites (Wasser et al., 1993). For carnivores, and other wildlife that consume other animals, their FGM levels could be altered by direct intake of glucocorticoids. For example, von der Ohe and Servheen (2002) speculated that circulating glucocorticoid levels in animals may be increased by the consumption of large amounts of glucocorticoids in animal flesh (e.g., fish) or other dietary sources.

Some reported seasonal patterns of FGMs (Huber et al., 2003; Millspaugh et al., 2001) might be partly related to seasonal differences in diet. For herbivores, fiber content as affected by the seasonality of plant phenology, might be particularly important in influencing seasonal patterns observed in FGMs. Despite the importance of this factor and ease with which it could be evaluated, it has not been addressed. Use of captive animals to test this assumption would be useful as would laboratory experiments to evaluate whether diet composition and quality affects FGM measures. We encourage researchers to evaluate this factor and if found to be important, it will become necessary to understand the animal's diet in relation to resulting FGM measures.

\subsubsection{Excretion route}

Metabolites from circulating steroid hormones are typically excreted via the urinary tract, the gastrointestinal tract, or both. Different steroid hormones are metabolized and excreted in various proportions via the urine and/or feces. For example, Bahr et al. (2000) reported that in marmosets, macaques, and chimpanzees, 82$91 \%$ of cortisol metabolites are excreted via the urine, whereas $9-18 \%$ are excreted in feces. Similarly, Teskey-Gerstl et al. (2000) reported for European hares, the average excretion rate of radiolabeled glucocorticoid metabolites in urine and feces were 91.5 and $8.5 \%$, respectively. Consequently, a particular FGM assay only measures some proportion of the total glucocorticoid metabolites produced by an animal. However, the assay is useful if the same relative proportion of glucocorticoid metabolites is always measured.

Collection of urine or feces in mammals is relatively straightforward; however, fecal samples collected from avian species are often contaminated by the uric acid portion of the excreta (Ludders et al., 2001; Washburn et al., 2003). Consequently, researchers must decide whether or not to separate the two portions prior to analysis. If the proportion of uric acid contaminating the feces varies among individual fecal samples, the amount of glucocorticoid metabolites could vary as well, thus increasing sample-to-sample variability (Ludders et al., 2001; Washburn et al., 2003). We believe this is an important area for future research; however, until such questions are answered we recommend researchers not separate the uric acid and fecal portions of bird droppings. In addition, by analyzing the fecal and uric acid portions together, a more comprehensive estimate of total glucocorticoid metabolites can be obtained.

\section{Conclusions}

Central to advancing FGM techniques is further evaluation of confounding factors, including sampling artifacts and biological factors. The existing literature demonstrates that sampling issues such as sample age, storage, and collection techniques, affect FGM measures. Biological factors including daily and seasonal patterns in glucocorticoid secretion, sex, age, and reproductive status of individual animals, and length of time in captivity must also be considered when designing experiments and interpreting results. Other factors such as diet composition and fecal sample mass should be further evaluated. Furthermore, it becomes important to consider the interactive effects of these factors. When considering the multiple sources of variation that exist in FGM studies, the propagation of these errors could result in so much error, that FGM estimates are essentially useless. Although we have offered general guidance on how to address some of these issues given existing 
literature, these general recommendations should be considered in light of study objectives and conditions. Given that all procedures introduce variation in measurement, researchers should carefully consider whether the variation introduced by field and laboratory procedures exceed the measurable variance introduced by the disturbance effects of interest.

A large unresolved issue impeding the utility of FGM assays in conservation biology and other fields is an understanding of what range of FGM concentration, over what period of time, is deleterious to the animal. We must remember that glucocorticoids maintain desirable properties (e.g., Holberton, 1999); they are adaptive mediators of the stress response by helping the animal redirect activities. They also play a critical role in glucose homeostasis and suppress stimulation of other body responses (e.g., immunological) that prevents damage to the body (Munck et al., 1984; Romero, 2004; Sapolsky et al., 2000). Thus, an increase in glucocorticoid secretion does not automatically equate to a state of distress (Moberg, 2000; Romero, 2004). Fecal glucocorticoid metabolite assays might help forewarn of important biological costs, such as reduced demographic vigor. However, we must first understand the relationship between the magnitude and duration of glucocorticoid secretion and performance. It must be recognized that elevated FGM concentrations do not automatically indicate distress. Elevated levels might forewarn of possible harm (Creel et al., 2002); however, we must be careful to avoid confusing elevated with deleterious responses. Instead, we must carefully consider whether observed FGM levels result in a significant biological cost that shifts energy away from normal processes (Moberg, 2000). The crisis nature of many decisions in conservation biology often requires decisions from limited data; however, confirmatory results should not be posited when data are incomplete or confounding factors are not understood. Building reliable databases, and research with surrogate species when possible, will aid future efforts and enhance the utility of FGM assays.

\section{Acknowledgments}

We thank the University of Missouri (MU) for financial and logistical support of our research over the past several years. Some of our work has been funded by a MU Research Board Grant, a MU Life Science Mission Enhancement Postdoctoral Fellowship, and the MU Department of Fisheries and Wildlife Sciences and Division of Biological Sciences. We thank the Missouri Department of Conservation for supporting much of our glucocorticoid work with mourning doves and white-tailed deer. Also, the South Dakota Department of Game, Fish, and Parks, Custer State Park, University of Washington, Woodland Park Zoo, and South Dakota State University have supported our prior research with elk. We thank J. Faaborg, R. Slotow, G. van Dyk, M. Milanick, S. Jones, J. Schadt, S. Chinnaduarai, S. Ganjum, D. Tempel, R. Gutiérrez, S. Wasser, K. Hunt, J. Schulz, L. Hansen, J. Beringer, and M. Leu for stimulating discussions regarding the use of FGM analyses. We thank T. Meyer, C. Rittenhouse, B. Woeck, J. Sumners, T. Mong, A. Knox, B. Hoenes, and $\mathrm{T}$. Bonnot for their assistance in collecting fecal samples and sample processing in our laboratory. R. Gitzen, B. Kernohan, several anonymous reviewers, and R. Dores provided helpful comments on the manuscript.

\section{References}

Aldercreutz, H., Martin, F., Pulkkinen, M., Dencker, H., Rimér, U., Sjöberg, N.-O., Tikkanen, M.J., 1976. Intestinal metabolism of estrogens. Journal of Clinical Endocrinology and Metabolism 43, 497-505.

Astheimer, L.B., Buttemer, W.A., Wingfield, J.C., 1992. Interactions of corticosterone with feeding, activity and metabolism in passerine birds. Ornis Scandinavia 23, 355-365.

Bahr, N., Palme, R., Möhle, U., Hodges, K., Heistermann, M., 2000. Comparative aspects of the metabolism and excretion of cortisol in three individual nonhuman primates. General and Comparative Endocrinology 117, 427-438.

Barnett, J.L., Hemsworth, P.H., Cronin, G.M., Newman, E.A., McCallum, T.H., 1991. Effects of design of individual cage-stalls on the behavior and physiological responses related to the welfare of pregnant pigs. Applied Animal Behavior Science 32, 23-34.

Bercovitz, A.B., Czekala, N.M., Lasley, B.L., 1978. A new method of sex determination in monomorphic birds. Journal of Zoo and Animal Medicine 9, 114-124.

Berkeley, E.V., Kirkpatrick, J.F., Schaffer, N.E., Bryant, W.M., Threlfall, W.R., 1997. Serum and fecal steroid analysis of ovulation, pregnancy, and parturition in the black rhinocerus (Diceros bicornis). Zoo Biology 16, 121-132.

Bokkenheuser, V.D., Winter, J., 1980. Biotransformation of steroid hormones by gut bacteria. American Journal of Clinical Nutrition 33, 2502-2506.

Breuner, C.W., Wingfield, J.C., Romero, L.M., 1999. Diel rhythms of basal and stress-induced corticosterone in a wild, seasonal vertebrate, Gambel's white-crowned sparrow. Journal of Experimental Zoology 284, 334-342.

Brown, J.L., Wasser, S.K., Wildt, D.E., Graham, L.H., 1994. Comparative aspects of steroid hormone metabolism and ovarian activity in felids, measured noninvasively in feces. Biology of Reproduction 51, 776-786.

Cook, C.J., Mellor, D.J., Harris, P.J., Ingram, J.R., Matthews, L.R., 2000. Hands-on and hands-off measurement of stress. In: Moberg, G.P., Mench, J.A. (Eds.), The Biology of Animal Stress. CABI Publishing, New York, New York, USA, pp. 123-146.

Craig, J.V., Craig, J.A., 1985. Corticosteroid levels in white leghorn hens as affected by handling, laying house environment, and genetic stock. Poultry Science 64, 809-816.

Creel, S., Fox, J.E., Hardy, A., Sands, J., Garrott, B., Peterson, R.O., 2002. Snowmobile activity and glucocorticoid stress responses in wolves and elk. Conservation Biology 16, 809-814.

Dawson, A., Howe, P.D., 1983. Plasma corticosterone in wild starlings (Sturnus vulgaris) immediately following capture and in relation to 
body weight during the annual cycle. General and Comparative Endocrinology 51, 303-308.

Dehnhard, M., Schreer, A., Krone, O., Jewgenow, K., Krause, M., Grossmann, R., 2003. Measurement of plasma corticosterone and fecal glucocorticoid metabolites in the chicken (Gallus domesticus), the great cormorant (Phalacrocorax carbo), and the goshawk (Accipiter gentiles). General and Comparative Endocrinology 131, 345-352.

Dehnhard, M., Clauss, M., Lechner-Doll, M., Meyer, H.H.D., Palme, R., 2001. Noninvasive monitoring of adrenocortical activity in roe deer (Capreolus capreolus) by measurement of fecal cortisol metabolites. General and Comparative Endocrinology 123, 111120.

Dufty Jr., A.M., Belthoff, J.R., 1997. Corticosterone and the stress response in young western screech-owls: effects of captivity, gender, and activity period. Physiological Zoology 70, 143-149.

Ewing, S.A., Lay Jr., D.C., von Borell, E., 1999. Farm Animal Wellbeing, Prentice Hall, Upper Saddle River, New Jersey, USA.

Foley, C.A.H., Papageorge, S., Wasser, S.K., 2001. Noninvasive stress and reproductive measures of social and ecological pressures in free-ranging African elephants. Conservation Biology 15, 1134 1142 .

Ganswindt, A., Palme, R., Heistermann, M., Borragan, S., Hodges, J.K., 2003. Non-invasive assessment of adrenocortical function in the male African elephant (Loxodonta africana) and its relation to musth. General and Comparative Endocrinology 134, 156-166.

Goldin, B.R., Adlercreutz, H., Gorbach, S.L., Warram, J.H., Dwyer, J.T., Swenson, L., Woods, M.N., 1981. Effect of diet on excretion of estrogen and pre- and post-menopausal woman. Cancer Research 41, 3771-3773.

Goldin, B.R., Adlercreutz, H., Gorbach, S.L., Warram, J.H., Dwyer, J.T., Swenson, L., Woods, M.N., 1982. Estrogen excretion patterns and plasma levels in vegetarian and omnivorous women. New England Journal of Medicine 307, 1542-1547.

Good, T., Khan, M.Z., Lynch, J.W., 2003. Biochemical and physiological validation of a corticosteroid radioimmunoassay for plasma and fecal samples in oldfield mice (Peromyscus polionotus). Physiology and Behavior 80, 405-411.

Goymann, W., Möstl, E., Van’t Hof, T., East, M.L., Hofer, H., 1999. Noninvasive fecal monitoring of glucocorticoids in spotted hyenas (Crocuta crocuta). General and Comparative Endocrinology 114, 340-348.

Goymann, W., Möstl, E., Gwinner, E., 2002. Corticosterone metabolites can be measured noninvasively in excreta of European stonechats (Saxicola torquata rubicola). Auk 119, 1167-1173.

Graham, L.H., Brown, J.L., 1996. Cortisol metabolism in the domestic cat and implications for non-invasive monitoring of adrenocortical function in endangered felids. Zoo Biology 15, 71-82.

Gregory, L.F., Schmid, J.R., 2001. Stress responses and sexing of wild Kemp's Ridley Sea Turtles (Lepidochelys kempii) in the Northeastern Gulf of Mexico. General and Comparative Endocrinology 124, 66-74.

Hadley, M.E., 1996. Endocrinology. Prentice-Hall, Upper Saddle River, New Jersey, USA.

Hamilton, G.D., Weeks Jr., H.P., 1985. Cortisol and aldosterone comparisons of cottontail rabbits collected by shooting, trapping, falconry. Journal of Wildlife Diseases 31, 40-42.

Harlow, H.J., Beck, T.D.I., Walters, L.M., Greenhouse, S.S., 1990. Seasonal serum glucose, progesterone, and cortisol levels of black bears (Ursus americanus). Canadian Journal of Zoology 68, 183187.

Harper, J.M., Austad, S.N., 2000. Fecal glucocorticoids: a noninvasive method of measuring adrenal activity in wild and captive rodents. Physiological and Biochemical Zoology 73, 12-22.

Harper, J.M., Austad, S.N., 2001. Effect of capture and season on fecal glucocorticoid levels in deer mice (Peromyscus maniculatus) and red-backed voles (Clethrionomys gapperi). General and Comparative Endocrinology 123, 337-344.

Hayssen, V., Harper, J.M., DeFina, R., 2002. Fecal corticosteroids in agouti and non-agouti deer mice (Peromyscus maniculatus). Comparative Biochemistry and Physiology A-Molecular and Integrative Physiology 132, 439-446.

Heath, J.A., Dufty Jr., A.M., 1998. Body condition and the adrenal stress response in captive American kestrel juveniles. Physiological Zoology 71, 67-73.

Holberton, R.L., 1999. Changes in patterns of corticosterone secretion concurrent with migratory fattening in a neotropical migratory bird. General and Comparative Endocrinology 116, 49-58.

Hood, L.C., Boersma, P.D., Wingfield, J.C., 1998. The adrenocortical response to stress in incubating magellanic penguins (Spheniscus magellanicus). Auk 115, 76-84.

Huber, S., Palme, R., Arnold, W., 2003. Effects of season, sex, and sample collection on concentrations of fecal cortisol metabolites in red deer (Cervus elaphus). General and Comparative Endocrinology $130,48-54$.

Hunt, K.E., Trites, A.W., Wasser, S.K., 2004. Validation of a fecal glucocorticoid assay for Stellar sea lions (Eumetopias jubatus). Physiology and Behavior 80, 595-601.

Joseph, M.M., Meier, A.H., 1973. Daily rhythms of plasma corticosterone in the Common Pigeon, Columba livia. General and Comparative Endocrinology 20, 326-330.

Jurke, M.H., Czekala, N.M., Lindburg, D.G., Millard, S.E., 1997. Fecal corticoid metabolite measurement in the cheetah (Acinonyx jabatus). Zoo Biology 16, 133-147.

Kenagy, G.J., Place, N.J., 2000. Seasonal changes in plasma glucocorticosteroids of free-living yellow pine chipmunks: effects of reproduction and capture and handling. General and Comparative Endocrinology 117, 189-199.

Khan, M.Z., Altmann, J., Isani, S.S., Yu, J., 2002. A matter of time: evaluating the storage of fecal samples for steroid analysis. General and Comparative Endocrinology 128, 57-64.

Kirkpatrick, J.F., McCarthy, J.C., Gudermuth, D.F., Shideler, S.E., Lasley, B.L., 1996. An assessment of the reproductive biology of Yellowstone bison (Bison bison) subpopulations using noncapture methods. Canadian Journal of Zoology 74, 8-14.

Le Maho, Y., Karmann, H., Briot, D., Handrich, Y., Robin, J.-P., Mioskowski, E., Cherel, Y., Farni, J., 1992. Stress in birds due to routine handling and how to avoid it. American Journal of Physiology 263, R775-R781.

Ludders, J.W., Langenberg, J.A., Czekala, N.M., Erb, H.N., 2001. Fecal corticosterone reflects serum corticosterone in Florida sandhill cranes. Journal of Wildlife Diseases 37, 646-652.

Lynch, J.W., Khan, M.Z., Altmann, J., Njahira, M.N., Rubenstein, N., 2003. Concentrations of four fecal steroids in wild baboons: short-term storage conditions and consequences for data interpretation. General and Comparative Endocrinology 132, 264 271.

Marra, P.P., Lampe, K.T., Tedford, B.L., 1995. Plasma corticosterone levels in two species of Zonotrichia sparrows under captive and free-living conditions. Wilson Bulletin 107, 296-305.

Mathies, T., Felix, T.A., Lance, V.A., 2001. Effects of trapping and subsequent short-term confinement stress on plasma corticosterone in the brown treesnake (Boiga irregularis) on Guam. General and Comparative Endocrinology 124, 106-114.

Matkovics, B., 1972. In vitro transformation of steroids as a substitute of microbial transformation. Steroids Lipids Research 3, 1-7.

Merl, S., Scherzer, S., Palme, R., Möstl, E., 2000. Pain causes increased concentrations of glucocorticoid metabolites in horse feces. Journal of Equine Veterinary Science 20, 586-590.

Miller, M.W., Hobbs, N.T., Sousa, M.C., 1991. Detecting stress responses in Rocky Mountain bighorn sheep (Ovis canadensis canadensis): reliability of cortisol concentrations in urine and feces. Canadian Journal of Zoology 69, 15-24. 
Millspaugh, J.J., Woods, R.J., Hunt, K.E., Raedeke, K.J., Brundige, G.C., Washburn, B.E., Wasser, S.K., 2001. Using fecal glucocorticoid assays to study the physiological stress response of elk. Wildlife Society Bulletin 29, 899-907.

Millspaugh, J.J., Washburn, B.E., Milanick, M.A., Beringer, J., Hansen, L.P., Meyer, T.M., 2002. Noninvasive techniques for stress assessment in white-tailed deer. Wildlife Society Bulletin 30, 899-907.

Millspaugh, J.J., Washburn, B.E., Milanick, M.A., Slotow, R., van Dyk, G., 2003. Effects of heat and chemical treatments on fecal glucocorticoid measurements: implications for sample transport. Wildlife Society Bulletin 31, 399-406.

Millspaugh, J.J., Washburn, B.E., 2003. Within-sample variation of fecal glucocorticoid measurements. General and Comparative Endocrinology 132, 21-26.

Moberg, G.P., 2000. Biological response to stress: implication for animal welfare. In: Moberg, G.P., Mench, J.A. (Eds.), The Biology of Animal Stress. CABI Publishing, New York, New York, USA, pp. 1-21.

Monfort, S.L., Schwartz, C.S., Wasser, S.K., 1993. Monitoring reproduction in captive moose using urinary and fecal steroid metabolites. Journal of Wildlife Management 57, 400-407.

Moore, I.T., Greene, M.J., Mason, R.T., 2001. Environmental and seasonal adaptations of the adrenocortical and gonadal responses to capture stress in two populations of the male garter snake, Thamnophis sirtalis. Journal of Experimental Zoology 289, 99-108.

Morrow, C.J., Kolver, E.S., Verkerk, G.A., Matthews, L.R., 2002. Fecal glucocorticoid metabolites as a measure of adrenal activity in dairy cattle. General and Comparative Endocrinology 126, 229241.

Möstl, E., Messmann, S., Bagu, E., Robia, C., Palme, R., 1999. Measurement of glucocorticoid metabolite concentrations in faeces of domestic livestock. Journal of Veterinary Medicine A 46, 621631.

Munck, A., Guyre, P.M., Holbrook, N.J., 1984. Physiological functions of glucocorticoids in stress and their relation to pharmacological actions. Endocrine Reviews 5, 25-44.

Möstl, E., Maggs, J.L., Schrotter, G., Besenfelder, U., Palme, R., 2002. Measurement of cortisol metabolites in faeces of ruminants. Veterinary Research Communications 26, 127-139.

Möstl, E., Palme, R., 2002. Hormones as indicators of stress. Domestic Animal Endocrinology 23, 67-74 (Special Issue).

Palme, R., Robia, C., Baumgartner, W., Möstl, E., 2000. Transport stress in cattle as reflected by an increase in faecal cortisol metabolite concentrations. Veterinary Record 146, 108-109.

Palme, R., Möstl, E., 1997. Measurement of cortisol metabolites in faeces of sheep as a parameter of cortisol concentration in blood. International Journal of Mammalian Biology 62, 192-197 (Suppl. 2).

Piersma, T., Ramenofsky, M., 1998. Long-term decreases of corticosterone in captive migrant shorebirds that maintain seasonal mass and moult cycles. Journal of Avian Biology 29, 97-104.

Raminelli, J.L.F., de Sousa, M.B.C., Cunha, M.S., Barbosa, M.F.V., 2001. Morning and afternoon patters of fecal cortisol excretion among reproductive and non-reproductive male and female common marmosets, Callithrix jacchus. Biological Rhythm Research $32,159-167$.

Rushen, J., 2000. Some issues in the interpretation of behavioural responses to stress. In: Moberg, G.P., Mench, J.A. (Eds.), The Biology of Animal Stress. CABI Publishing, New York, New York, USA, pp. 23-42.

Romero, L.M., 2002. Seasonal changes in plasma glucocorticoid concentrations in free-living vertebrates. General and Comparative Endocrinology 128, 1-24.

Romero, L.M., 2004. Physiological stress in ecology: lessons from biomedical research. Trends in Ecology and Evolution 19, 249-255.

Romero, L.M., Ramenofsky, M., Wingfield, J.C., 1997. Season and migration alters the corticosterone response to capture and handling in an arctic migrant, the white-crowned sparrow (Zonotrichia leucophrys gambelli). Comparative Biochemistry and Physiology C 116, 171-177.

Romero, L.M., Remage-Healey, L., 2000. Daily and seasonal variation in response to stress in captive starlings (Sturnus vulgaris): corticosterone. General and Comparative Endocrinology 119, 52-59.

Romero, L.M., Soma, K.K., Wingfield, J.C., 1998a. Changes in pituitary and adrenal sensitivities allow the snow bunting (Plectrophenax nivalis), an arctic-breeding song bird, to modulate corticosterone release seasonally. Journal of Comparative Physiology B 168, 353-358.

Romero, L.M., Soma, K.K., Wingfield, J.C., 1998b. Hypothalamicpituitary-adrenal axis changes allow seasonal modulation of corticosterone in a bird. American Journal of Physiology 274, R1338-R1344.

Romero, L.M., Soma, K.K., Wingfield, J.C., 1998c. The hypothalamus and adrenal regulate modulation of corticosterone release in redpolls (Carduelis flammea, an arctic-breeding song bird). General and Comparative Endocrinology 109, 347-355.

Romero, L.M., Wingfield, J.C., 1998d. Seasonal changes in adrenal sensitivity alter corticosterone levels in Gambel's white-crowned sparrows (Zonotrichia leucophrys gambelii). Comparative Biochemistry and Physiology C 119, 31-36.

Romero, L.M., Wingfield, J.C, 1999. Alterations in hypothalamicpituitary-adrenal function associated with captivity in Gambel's white-crowned sparrows (Zonotrichia leucophrys gambelii). Comparative Biochemistry and Physiology B 122, 13-20.

Sapolsky, R.M., Romero, L.M., Munck, A.U., 2000. How do glucocorticoids influence stress-responses? Integrating permissive, suppressive, stimulatory, and adaptive actions. Endocrine Reviews 21, 55-89.

Smith, G.T., Wingfield, J.C., Veit, R.R., 1994. Adrenocortical response to stress in the common diving petrel, Pelecanoides urinatrix. Physiological Zoology 67, 526-537.

Suedkamp Wells, K.M., Washburn, B.E., Millspaugh, J.J., Ryan, M.R., Hubbard, M., 2003. Effects of radiotransmitters on fecal glucocorticoid levels in captive dickcissels. Condor 105, 805-810.

Tempel, D.J., Gutiérrez, R.J., 2003. Fecal corticosterone levels in California Spotted Owls exposed to low-intensity chainsaw sound. Wildlife Society Bulletin 31, 698-702.

Tempel, D.J., Gutiérrez, R.J., 2004. Factors related to fecal corticosterone levels in California Spotted Owls: implications for assessing chronic stress. Conservation Biology 18, 538-547.

Terio, K.A., Brown, J.L., Moreland, R., Munson, L., 2002. Comparison of different drying and storage methods on quantifiable concentrations of fecal steroids in the Cheetah. Zoo Biology 21, 215-222.

Teskey-Gerstl, A., Bamberg, E., Steineck, T., Palme, R., 2000. Excretion of corticosteroids in urine and faeces of hares. Journal of Comparative Physiology B 170, 163-168.

Touma, C., Sachser, N., Möstl, E., Palme, R., 2003. Effects of sex and time of day on metabolism and excretion of corticosterone in urine and feces of mice. General and Comparative Endocrinology 130, 267-278.

Touma, C., Palme, R., Sachser, N., 2004. Analyzing corticosterone metabolites in fecal samples of mice: a noninvasive technique to monitor stress hormones. Hormones and Behavior 45, 10-22.

Turner Jr., J.W., Nemeth, R., Rogers, C., 2003. Measurement of fecal glucocorticoids in parrotfishes to assess stress. General and Comparative Endocrinology 133, 341-352.

von der Ohe, C.G., Servheen, C., 2002. Measuring stress in mammals using fecal glucocorticoids: opportunities and challenges. Wildlife Society Bulletin 30, 1215-1225.

Washburn, B.E., Millspaugh, J.J., 2002. Effects of simulated environmental conditions on glucocorticoid metabolite measurements in white-tailed deer feces. General and Comparative Endocrinology 127, 217-222. 
Washburn, B.E., Morris, D.L., Millspaugh, J.J., Faaborg, J., Schulz, J.H., 2002. Using a commercially available radioimmunoassay to quantify corticosterone in avian plasma. Condor 104, 558-563.

Washburn, B.E., Millspaugh, J.J., Schulz, J.H., Jones, S.B., Mong, T.W., 2003. Using fecal glucocorticoids for stress assessment in mourning doves. Condor 105, 696-706.

Washburn, B.E., Tempel, D.J., Millspaugh, J.J., Gutiérrez, R.J., Seamans, M.E., 2004. Factors related to fecal estrogens and fecal testosterone in California spotted owls. Condor 106, 567-579.

Wasser, S.K., Thomas, R., Lair, P.P., Guidry, C., Southers, J., Lucas, J., Wildt, D.E., Monfort, S.L., 1993. Effects of dietary fibre on faecal steroid measurements in baboons (Papio cynocephalus cynocephalus). Journal of Reproduction and Fertility 97, 569-574.

Wasser, S.K., Papageorge, S., Foley, C., Brown, J.L., 1996. Excretory fate of estradiol and progesterone in the African elephant (Loxodonta africana) and patterns of fecal steroid concentrations throughout the estrous cycle. General and Comparative Endocrinology 102, 255-262.

Wasser, S., Bevis, K., King, G., Hanson, E., 1997. Non-invasive physiological measures of disturbance in the northern spotted owl. Conservation Biology 11, 1019-1022.

Wasser, S.K., Hunt, K.E., Brown, J.L., Cooper, K., Crockett, C.M., Bechert, U., Millspaugh, J.J., Larson, S., Monfort, S.L., 2000. A generalized fecal glucocorticoid assay for use in a diverse array of non-domestic mammalian and avian species. General and Comparative Endocrinology 120, 260-275.

Whitten, P.L., Brockman, D.K., Stavisky, R.C., 1998. Recent advances in noninvasive techniques to monitor hormone-behavior interactions. Yearbook of Physical Anthropology 41, 1-23.
Whittier, J.M., Corrie, F., Limpus, C., 1997. Plasma steroid profiles in nesting loggerhead turtles (Caretta caretta) in Queensland, Australia: relationship to nesting episode and season. General and Comparative Endocrinology 106, 39-47.

Widmaier, E.P., Harmer, T.L., Sulak, A.M., Kunz, T.H., 1994. Further characterization of the pituitary-adrenocortical responses to stress in chiroptera. The Journal of Experimental Zoology 269, 442-449.

Wielebnowski, N.C., Fletchall, N., Carlstead, K., Busso, J.M., Brown, J.L., 2002. Noninvasive assessment of adrenal activity associated with husbandry and behavioral factors in the North American clouded leopard population. Zoo Biology 21, 77-98.

Windle, R.J., Wood, S.A., Lightman, S.L., Ingram, C.D., 1998. The pulsatile characteristics of hypothalamo-pituitary-adrenal activity in female Lewis and Fischer 344 rats and its relationship to differential stress responses. Endocrinology 139, 4044-4052.

Wingfield, J.C., Smith, J.P., Farner, D.S., 1982. Endocrine responses of white-crowned sparrows to environmental stress. Condor 84 , 399-409.

Wingfield, J.C., 1994. Modulation of the adrenocortical response to stress in birds. in: K.G. Davey, R.E. Peter, S.S. Tobe, (Eds.), Perspectives in Comparative Endocrinology National Research Council of Canada, Ottawa, Canada, pp. 520-528.

Wingfield, J.C., Suydam, R., Hunt, K., 1994. The adrenocortical responses in snow buntings (Plectrophenax nivalis) and Lapland longspurs (Calcarius lapponicus) at Barrow, Alaska. Comparative Biochemistry and Physiology B 108, 299-306.

Woods, G.F., 1975. Chemical and microbiological transformation of steroids. In: Cameron, E.H.D., Hillier, S.G., Griffiths, K. (Eds.), Steroid Immunoassay. Alpha Omega, Cardiff, pp. 5-10. 